\title{
Cytokine alterations in first-episode schizophrenia patients before and after antipsychotic treatment
}

\author{
Lot de Witte $^{\mathrm{a}, 1}$, Jakub Tomasik b,c,1 Emanuel Schwarz $^{\mathrm{b}}$, Paul C. Guest ${ }^{\mathrm{b}}$, Hassan Rahmoune ${ }^{\mathrm{b}}$, \\ René S. Kahn ${ }^{\text {a }}$, Sabine Bahn ${ }^{\text {b,c,* }}$ \\ a Department of Psychiatry, University of Utrecht, Heidelberglaan 100, 3584 CX Utrecht, The Netherlands \\ b Department of Chemical Engineering and Biotechnology, Tennis Court Road, Cambridge CB21QT, University of Cambridge, UK \\ ' Department of Neuroscience, Erasmus Medical Centre, Dr. Molewaterplein 50, 3015 GE, Rotterdam, The Netherlands
}

\section{A R T I C L E I N F O}

\section{Article history:}

Received 24 July 2013

Received in revised form 23 January 2014

Accepted 6 February 2014

Available online 26 February 2014

\section{Keywords:}

Schizophrenia

Immune system

Cytokines

Antipsychotics

Multiplex immunoassay

Biomarkers

\begin{abstract}
A B S T R A C T
Schizophrenia has been associated with central nervous system and peripheral immune system imbalances. However, most studies have not yielded conclusive results due to limitations such as small sample size, dissimilarities in the clinical status of patients and the high variability of cytokine levels within the normal human population. Here, we have attempted to account for these limitations by carrying out standardised multiplex immunoassay analyses of 9 cytokines in serum from 180 antipsychotic-naïve first-episode schizophrenia patients and 350 matched controls across 5 clinical cohorts. All subjects were matched for potential confounding factors including age, gender, smoking and body mass index. We found that the levels of interleukin (IL)-1RA, IL-10 and IL-15 were increased significantly in patients across the cohorts. We also found that the levels of IL-1RA and IL-10 were decreased in 32 patients who had been followed up and treated for 6 weeks with atypical antipsychotics. Interestingly, we found that the changes in IL-10 levels were significantly correlated with the improvements in negative, general and total symptom scores. These results indicate that mixed pro- and anti-inflammatory responses may be altered in first onset patients, suggesting a role in the aetiology of schizophrenia. The finding that only the anti-inflammatory cytokine IL-10 responded to treatment in parallel with symptom improvement suggests that this could be used as a potential treatment response biomarker in future studies of schizophrenia.
\end{abstract} (c) 2014 Elsevier B.V. All rights reserved.

\section{Introduction}

Schizophrenia is a severe psychiatric disorder with a complex and heterogeneous aetiology. Previous studies have indicated that alterations in immune system function may be involved in the disease process in at least a subgroup of patients (Drexhage et al., 2010; Muller and Schwarz, 2010). Well-established risk factors for schizophrenia include auto-immune and allergic diseases (Eaton et al., 2006; Pedersen et al., 2012), genetic variations in the human leukocyte antigen (HLA)region on chromosome 6 (Stefansson et al., 2009), winter and spring birth seasons (Davies et al., 2003), and perinatal and childhood infections (Dalman et al., 2008). Other evidence for immune system dysfunction in schizophrenia include the finding of activated microglia in the

\footnotetext{
* Corresponding author at: Department of Chemical Engineering and Biotechnology, Tennis Court Road, Cambridge CB21QT, University of Cambridge, UK. Tel.: + 441223334151. E-mail addresses: 1.d.dewitte@umcutrecht.nl (L.de Witte), jt455@cam.ac.uk (J. Tomasik), es404@cam.ac.uk (E. Schwarz),pg110@hermes.cam.ac.uk (P.C. Guest), hr288@cam.ac.uk (H. Rahmoune), r.kahn@umcutrecht.nl (R.S. Kahn), sb209@cam.ac.uk (S. Bahn).

1 These authors contributed equally.
}

brain (van Berckel et al., 2008; Doorduin et al., 2009) and altered levels of cytokines and other inflammatory markers in the cerebrospinal fluid and blood (Potvin et al., 2008; Miller et al., 2011). These findings suggest that the immune system may constitute a potential target for novel treatment approaches in schizophrenia. Indeed, recent clinical trials have shown that augmentation of antipsychotic treatment with nonsteroidal anti-inflammatory drugs (NSAIDs) improves symptoms in schizophrenia patients (Sommer et al., 2011).

The finding that immune alterations in schizophrenia have been found within the brain and cerebrospinal fluid, as well as in peripheral systems such as blood serum and leukocytes, suggests that systemic inflammatory processes are involved in schizophrenia pathogenesis (Maino et al., 2007; Potvin et al., 2008; Chan et al., 2011; Drexhage et al., 2011a,b; Miller et al., 2011; Schwarz et al., 2012). A previously published meta-analysis of 14 studies on serum cytokine alterations in first-episode schizophrenia patients ( $\mathrm{N}$ between 4 and 83 ) found increased levels of interleukin (IL)-1 $\beta$, IL-6, IL-12, tumour necrosis factor (TNF)- $\alpha$, transforming growth factor (TGF)- $\beta$, interferon (IFN)- $\gamma$ and soluble IL-2-receptor, although significant heterogeneity was observed across the different studies (Miller et al., 2011). This may be due to the small sample size, differences in inclusion and exclusion criteria, 
the use of diverse and non-standardised assay platforms, the sporadic presence of inflammatory or metabolic co-morbidities, and the large variability of serum cytokine levels within the normal human population (O'Connor et al., 2009). Moreover, peripheral inflammatory markers can be affected by confounding factors such as age, gender, smoking, weight and anti-psychotic medication (Park et al., 2005; Zhang et al., 2008; Miller et al., 2011). Therefore, larger sample numbers, stringent inclusion and exclusion criteria, and control of confounding factors are needed to draw reliable conclusions.

With this in mind, we have used a multiplex immunoassay to measure the levels of 9 cytokines in serum of antipsychotic-naïve first-episode schizophrenia patients and controls matched for age and gender. We also attempted to control for body mass index (BMI) and smoking, although this information was not available for all subjects. The main aim was to assess the reproducibility of cytokine alterations across independent cohorts to gain further insight into the role of these molecules in the aetiology of schizophrenia. In addition, we also carried out a pilot study to investigate cytokine changes in a subgroup of these patients who were treated with antipsychotics for 6 weeks.

\section{Material and methods}

\subsection{Clinical samples}

First onset and antipsychotic-naïve schizophrenia patients are difficult to obtain since annual recruitment rates range from 10 to 15 subjects for most clinical centres. We recruited subjects in collaboration with three centres in Germany and one in The Netherlands over a period of 10 years (Table 1). Cohort 1 was from the Department of Psychiatry, University of Cologne. Cohort 2 was recruited at the Department of Psychiatry, University of Muenster. Cohorts 3 and 5 were from the Department of Psychiatry, University of Magdeburg and cohort 4 was from the Erasmus Medical Centre in The Netherlands. A subgroup of patients ( $\mathrm{n}=32$; Table 2 ) from cohort 3 was used in follow-up studies to investigate antipsychotic treatment effects. The respective institutional ethical committees approved the study protocols and written informed consent was given by all participants. All studies were conducted according to the Declaration of Helsinki. Diagnoses were carried out by experienced psychiatrists using the Diagnostic and Statistical Manual of Mental Disorders-IV (DSM-IV) criteria and patients were assessed for psychopathology using the Positive and Negative Syndrome Scale (PANSS) (Kay et al., 1987). All clinical tests were performed according to Good Clinical Practice Guidelines. Healthy controls were recruited from the same hospitals and associated universities and matched the

\section{Table 2}

Demographic details of patients used for investigating drug effects. Patients were assessed before (T0) and after (T6) 6 week treatment with different antipsychotics (ola $=$ olanzapine; quet $=$ quetiapine; risp $=$ risperidone; $\operatorname{mix}=\operatorname{mix}$ of different antipsychotics).

\begin{tabular}{ll}
\hline Number & 32 \\
Treatment (ola/quet/risp/mix) & $7 / 7 / 9 / 9$ \\
Gender (M/F) & $22 / 10$ \\
Age & $31.2 \pm 10.5$ \\
BMI T0 & $24.0 \pm 4.4$ \\
BMI T6 & $24.7 \pm 3.9^{* *}$ \\
Smoking (Y/N) & $23 / 9$ \\
Cannabis (Y/N) & $9 / 23$ \\
Antipsychotic-naïve at T0 & 32 \\
PANSS positive score T0 & $21.5 \pm 6.5$ \\
PANSS negative score T0 & $18.3 \pm 8.9$ \\
PANSS general psychopathology score T0 & $42.4 \pm 12.1$ \\
PANSS positive score T6 & $11.7 \pm 3.9^{* * *}$ \\
PANSS negative score T6 & $14.2 \pm 6.5^{* *}$ \\
PANSS general psychopathology score T6 & $28.1 \pm 8.6^{* * *}$ \\
\hline
\end{tabular}

$\mathrm{M} / \mathrm{F}=$ male/female, $\mathrm{BMI}=$ body mass index, $\mathrm{Y} / \mathrm{N}=$ yes $/$ no, na $=$ not available. Values are shown as mean $\pm \mathrm{sd}$.

** $\mathrm{p}<0.01$.

$* * * \quad \mathrm{p}<0.001$ (Wilcoxon signed-rank test).

respective patient populations for age, gender and body mass index (BMI). Patients and controls with a family history of mental disease or other serious medical conditions such as type II diabetes mellitus, hypertension, cardiovascular or autoimmune diseases were excluded from the study. The study protocol, clinical samples and test methods were carried out in compliance with the Standards for Reporting of Diagnostic Accuracy (STARD) initiative (Bossuyt and Reitsma, 2003).

\subsection{Sample preparation}

Blood samples were collected in the morning into S-Monovette $7.5 \mathrm{~mL}$ serum tubes (Sarstedt, Numbrecht, Germany). The serum was prepared according to standard protocols by leaving the samples at room temperature for $2 \mathrm{~h}$ to allow clotting, followed by centrifugation at $4000 \mathrm{~g}$ for $5 \mathrm{~min}$ to remove clotted cells and other debris. The resulting supernatants were stored at $-80{ }^{\circ} \mathrm{C}$ in Lo-Bind Eppendorf tubes (Hamburg, Germany) prior to analysis.

\subsection{Multiplexed immunoassay analyses}

The levels of 21 serum cytokines were measured using a HumanMAP immunoassay platform as described previously (Schwarz et al., 2010).

Table 1

Demographic details of patients from the analysed cohorts.

\begin{tabular}{|c|c|c|c|c|c|c|}
\hline Cohort & 1 & 2 & 3 & 4 & 5 & Total \\
\hline Centre & Cologne, Germany & Muenster, Germany & Magdeburg, Germany & Rotterdam, Netherlands & Magdeburg, Germany & - \\
\hline $\mathrm{N}$ & 130 & 92 & 183 & 54 & 71 & 530 \\
\hline Patients n & 71 & 46 & 33 & 14 & 16 & 180 \\
\hline Controls n & 59 & 46 & 150 & 40 & 55 & 350 \\
\hline Patients (M/F) & $42 / 29$ & $35 / 11$ & $22 / 11$ & $11 / 3$ & $8 / 8$ & $118 / 62$ \\
\hline Controls (M/F) & $31 / 28$ & $35 / 11$ & $79 / 71$ & $33 / 7$ & $28 / 27$ & $206 / 144$ \\
\hline Patients age & $31 \pm 10$ & $27 \pm 9$ & $31 \pm 10^{*}$ & $24 \pm 7$ & $35 \pm 11$ & $30 \pm 10$ \\
\hline Controls age & $30 \pm 8$ & $27 \pm 9$ & $36 \pm 10$ & $27 \pm 4$ & $34 \pm 10$ & $32 \pm 10$ \\
\hline Patients BMI & $24 \pm 5$ & $22 \pm 2$ & $26 \pm 5$ & na & $22 \pm 3$ & na \\
\hline Controls BMI & $23 \pm 4$ & na & $24 \pm 4$ & na & $23 \pm 3$ & na \\
\hline Patients tobacco (Y/N/na) & $25 / 23 / 23$ & $16 / 26 / 4$ & $24 / 9 / 0^{*}$ & $10 / 4 / 0$ & $6 / 9 / 1$ & $81 / 71 / 28$ \\
\hline Controls tobacco $(\mathrm{Y} / \mathrm{N} / \mathrm{na})$ & $25 / 34 / 0$ & na & $41 / 109 / 0$ & na & $12 / 42 / 1$ & na \\
\hline Patients cannabis (Y/N/na) & $33 / 22 / 16$ & $15 / 27 / 4$ & $9 / 24 / 0$ & $8 / 6 / 0$ & $0 / 15 / 1$ & $65 / 94 / 21$ \\
\hline Controls cannabis (Y/N/na) & $31 / 25 / 3$ & na & $2 / 148 / 0$ & na & $0 / 55 / 0$ & na \\
\hline Antipsychotic-naïve patients & All & All & All & All & All & All \\
\hline PANSS positive item score & $23 \pm 6$ & $18 \pm 7$ & $21 \pm 6$ & na & $19 \pm 8$ & na \\
\hline PANSS negative item score & $23 \pm 8$ & $18 \pm 7$ & $19 \pm 9$ & na & $16 \pm 4$ & na \\
\hline Sample storage time (years) & $6.9 \pm 2.6$ & na & na & $2.5 \pm 1.1$ & na & na \\
\hline
\end{tabular}

$\mathrm{M} / \mathrm{F}=$ male/female, $\mathrm{BMI}=$ body mass index, $\mathrm{Y} / \mathrm{N}=$ yes/no (based on interview), na = not available. Values are shown as mean $\pm \mathrm{sd}$.

* $\mathrm{p}<0.05$ (Mann-Whitney test). 
The same platform has been successfully applied in a number of immunological (Ottervald et al., 2010; Wagner et al., 2012) and psychiatric (Domenici et al., 2010; Schwarz et al., 2010) studies for identification of biomarker candidates. The assays were performed in a Clinical Laboratory Improvement Amendments-certified laboratory at Myriad-RBM (Austin, TX, USA). In brief, assays were calibrated and absolute protein concentrations were determined using duplicate 8-points standard antigen curves. Assay performance was verified using quality control serum samples.

\subsection{Statistical analyses}

Assays for 9 cytokines [interferon (IFN)- $\gamma$, interleukin (IL)- $1 \alpha$, IL-1RA, IL-5, IL-10, IL-12p40, IL-15, IL-18 and tumour necrosis factor (TNF)- $\alpha$ ] fulfilled the following strict inclusion criteria and were therefore included in the study: 1) measurement in all 5 cohorts, 2) only one cohort with more than $80 \%$ missing data allowed and 3 ) did not show a significant correlation with sample storage time. To account for missing values in the measurement of specific analytes, readings below the lower limit of quantitation were replaced with half the minimum value. Analysis of covariance (ANCOVA) indicated that the levels of most cytokines varied significantly across the cohorts ( $\mathrm{p}$ value for the group $*$ cohort interaction $<0.05$ ). Therefore, each cohort was analysed for cytokine alterations individually.

The application of Shapiro-Wilk tests indicated that none of the measured analyte values were normally distributed $(p<0.05)$. Therefore, Cliff's delta was chosen as a non-parametric estimate of effect size and calculated for each cohort (Cliff, 1993). To obtain an overall effect size, the estimates determined for individual cohorts were combined without weighting. Unweighted Cliff's delta has been shown to outperform parametric effect size estimates such as Hedge's $g$ and Cohen's $d$ in terms of bias under non-normality and variance heterogeneity conditions (Kromrey et al., 2005). This approach minimised any strong influence of individual cohorts on the overall effect size, which could give rise to centre-specific findings. Confidence intervals for the overall Cliff's delta estimates were determined using the adjusted bootstrap percentile interval (bias corrected and accelerated, $\mathrm{BC}_{\mathrm{a}}$ ) (Efron, 1987). This method finds approximate confidence intervals based on the percentiles of the bootstrap distribution derived from re-sampling the set of effect sizes 5000 times determined from all cohorts. For assessment of the changes in cytokine levels following antipsychotic treatment, nonparametric Wilcoxon signed-rank tests were applied. Spearman correlation testing was also performed to determine if any analyte showed a significant correlation with symptom improvement ( $\triangle$ PANSS). All analyses were carried out using the free software package $\mathrm{R}$ (http://cran.rproject.org/) and GraphPad Prism.

\section{Results}

\subsection{Patient characteristics}

The serum samples were obtained from 180 first-episode antipsychotic-naïve schizophrenia patients and 350 healthy controls matched for age and gender (Table 1). Patients and controls were also matched for BMI and smoking in cases where this information was available. As an exception, cohort 3 showed significant differences in the age of patients and the distribution of smokers in relation to controls. The patients in all cohorts had high average scores for PANSS a
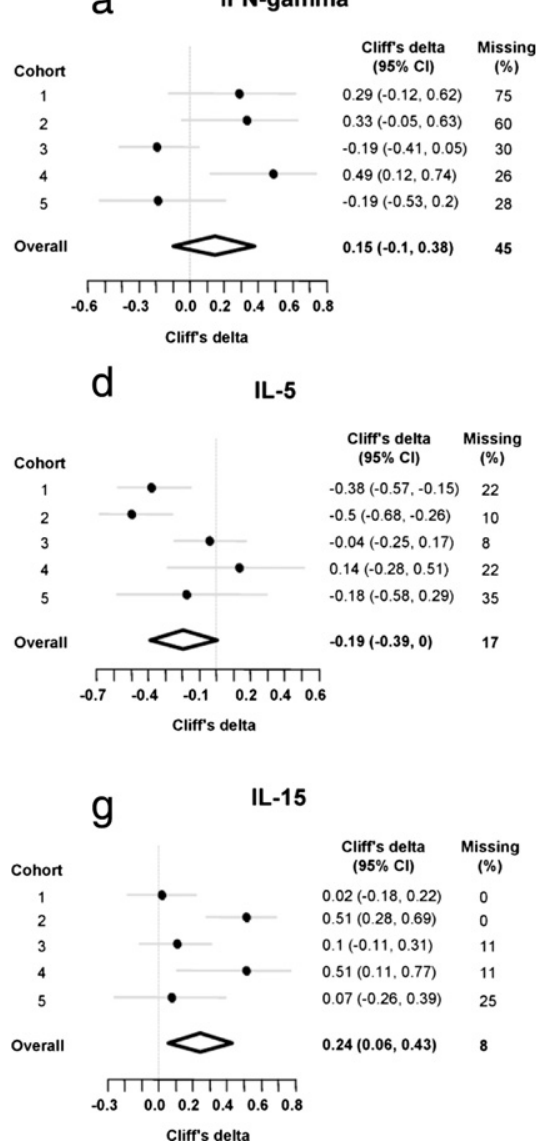

b

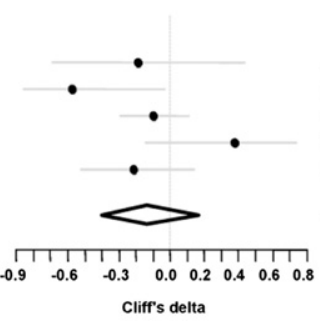

e

IL-10

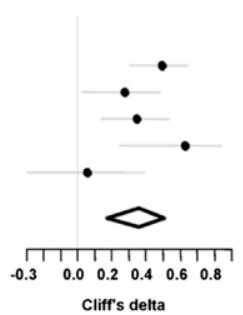

$\mathrm{h}$

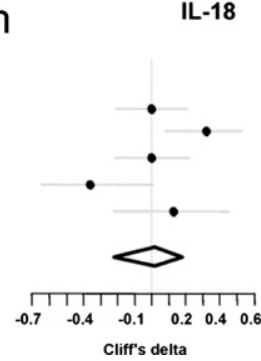

C
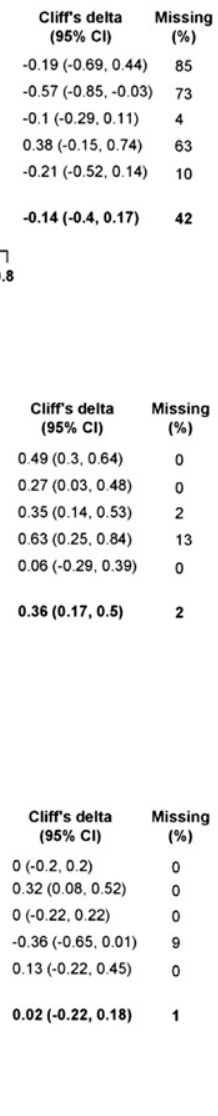

$f$
IL-1 ra

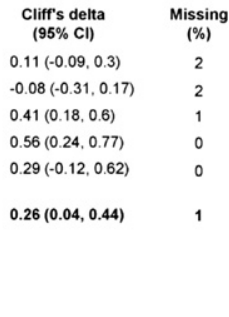

IL-12p40

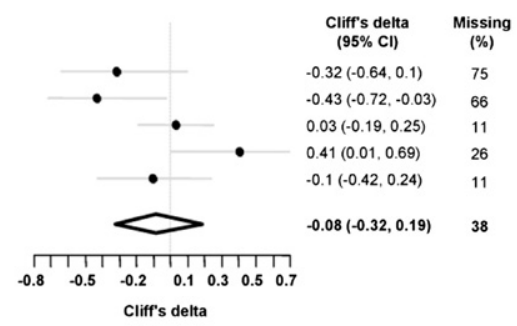

TNF-alpha


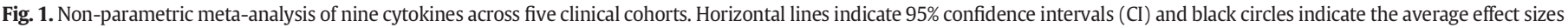

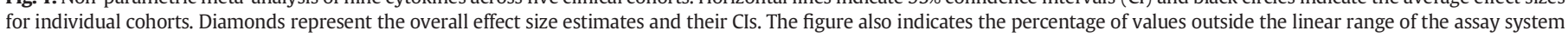
[missing (\%)]. 
Table 3

Changes in cytokine levels following 6 week treatment with atypical antipsychotics. Reproducible significant findings are shaded.

\begin{tabular}{|c|c|c|c|c|c|c|c|c|c|c|}
\hline \multirow[t]{2}{*}{ Cytokine } & \multicolumn{2}{|c|}{$\begin{array}{l}\text { All patients } \\
\qquad(\mathrm{n}=32)\end{array}$} & \multicolumn{2}{|c|}{$\begin{array}{l}\text { Quetiapine } \\
\qquad(\mathrm{n}=7)\end{array}$} & \multicolumn{2}{|c|}{$\begin{array}{c}\text { Mix of } \\
\text { antipsychotics } \\
(\mathrm{n}=9)\end{array}$} & \multicolumn{2}{|c|}{$\begin{array}{l}\text { Risperidone } \\
\qquad(\mathrm{n}=9)\end{array}$} & \multicolumn{2}{|c|}{$\begin{array}{l}\text { Olanzapine } \\
\qquad(\mathrm{n}=7)\end{array}$} \\
\hline & $\mathrm{RC}$ & p value & $\mathrm{RC}$ & $\mathrm{p}$ value & $\mathrm{RC}$ & $\mathrm{p}$ value & $\mathrm{RC}$ & p value & $\mathrm{RC}$ & $\mathrm{p}$ value \\
\hline IFN $-\gamma$ & 0.99 & 1.000 & 1.10 & 0.553 & 1.40 & 0.527 & 0.95 & 0.752 & 0.50 & 0.219 \\
\hline IL- $1 \alpha$ & 0.91 & 0.299 & 1.00 & 1.000 & 1.05 & 0.820 & 0.82 & 0.203 & 0.85 & 0.578 \\
\hline IL-1-RA & 0.76 & 0.005 & 0.82 & 0.141 & 1.23 & 0.820 & 0.53 & 0.035 & 0.64 & 0.047 \\
\hline IL-5 & 0.95 & 0.510 & 1.09 & 0.578 & 0.86 & 0.353 & 0.74 & 0.050 & 1.26 & 0.352 \\
\hline IL-10 & 0.86 & 0.059 & 0.91 & 0.834 & 1.02 & 0.933 & 0.79 & 0.042 & 0.73 & 0.036 \\
\hline IL-12p40 & 0.87 & 0.223 & 1.11 & 0.834 & 1.02 & 0.933 & 0.53 & 0.021 & 1.10 & 0.578 \\
\hline IL-15 & 0.94 & 0.495 & 0.76 & 0.469 & 1.15 & 0.575 & 0.93 & 0.800 & 0.88 & 0.675 \\
\hline IL-18 & 1.01 & 0.666 & 1.17 & 0.297 & 1.14 & 0.374 & 0.84 & 0.014 & 0.94 & 0.469 \\
\hline TNF- $\alpha$ & 1.28 & 0.070 & 1.68 & 0.059 & 0.83 & 0.529 & 1.08 & 0.800 & 2.16 & 0.100 \\
\hline
\end{tabular}

$\mathrm{RC}=$ ratio change; $\mathrm{p}$ values were calculated with Wilcoxon signed-rank tests.

positive and negative scores and were antipsychotic-naïve at the time of blood collection.

\subsection{Cytokine alterations in schizophrenia}

The serum concentrations of 9 cytokines were measured by multiplexed immunoassay analysis. This showed that the levels of these cytokines were not distributed uniformly across the cohorts. Since the distributions of age, gender, BMI and smoking were not significantly different, it is likely that other confounding factors which had not been controlled might have affected the results. To account for this possibility, we performed a non-parametric meta-analysis to determine the reproducibility of cytokine alterations across the 5 cohorts. This showed that 3 analytes (IL-1RA, IL-10 and IL-15) were reproducibly increased in first-onset schizophrenia patients compared to controls (Fig. 1c, e and g). The most robust change was observed for IL- 10 with average Cliff's delta reading of 0.36 and only $2 \%$ missing values.

Secondary analyses revealed that levels of IL-18 were significantly higher in smoking patients from cohort 3 ( 1.33 fold change, $\mathrm{p}=0.017$ ) and cohort 5 ( 3.91 fold change, $p=0.008$ ) when compared to nonsmoking patients. However, these effects were not reproducible in the remaining cohorts. In addition, no reproducible effects were observed with cannabis use or BMI, although this analysis was limited to only those patients for whom data on smoking, cannabis use and BMI was available.
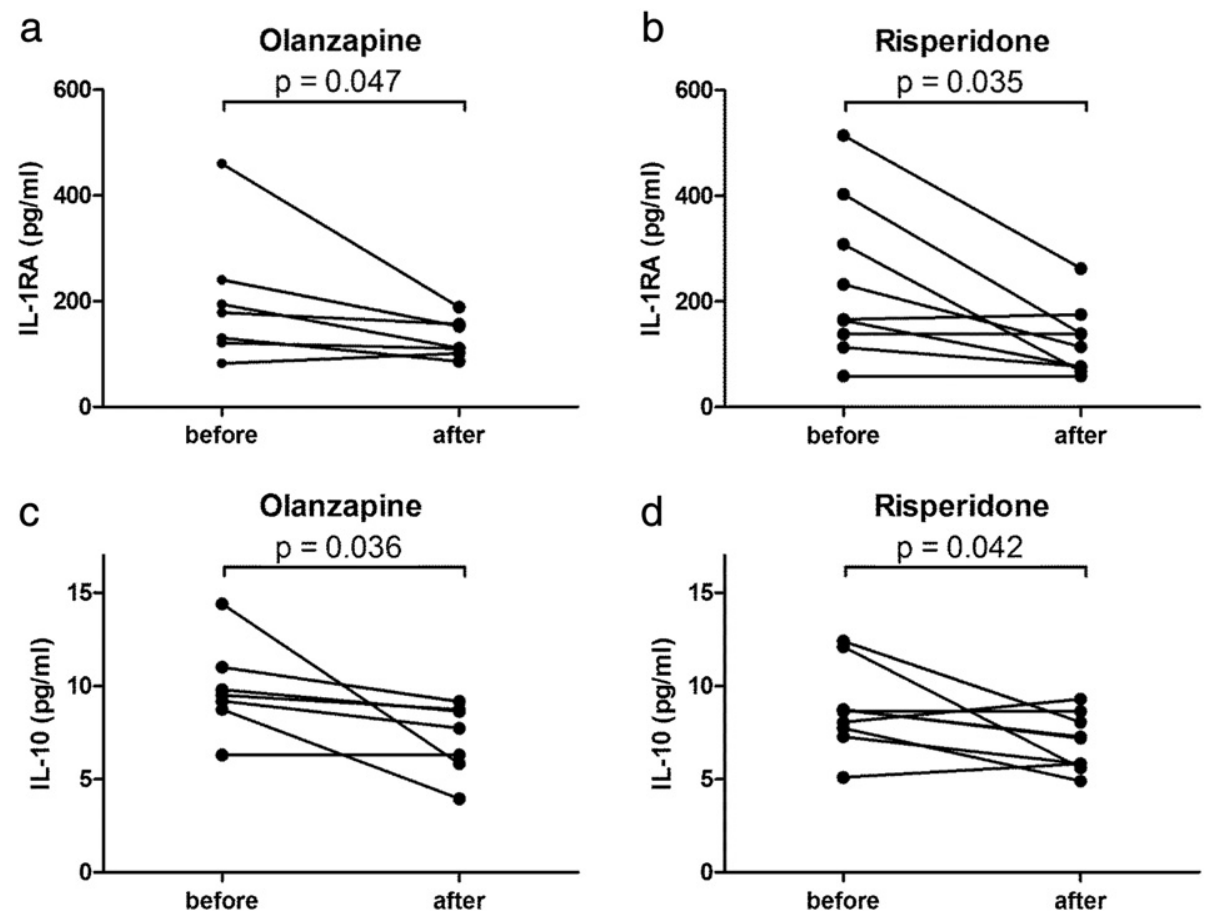

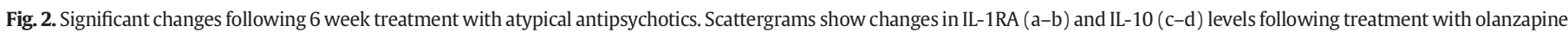

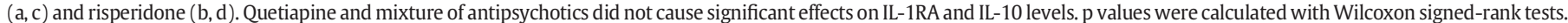


Table 4

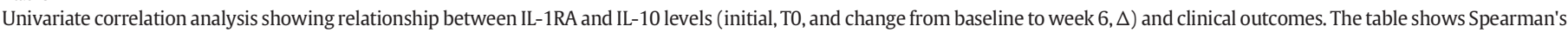
correlation coefficients rho and corresponding p values (in brackets). Significant correlations are shaded.

\begin{tabular}{|c|c|c|c|c|c|}
\hline & $\begin{array}{l}\triangle \text { PANSS } \\
\text { positive }\end{array}$ & $\begin{array}{l}\triangle \text { PANSS } \\
\text { negative }\end{array}$ & $\begin{array}{l}\triangle \text { PANSS } \\
\text { general }\end{array}$ & $\begin{array}{c}\triangle \text { PANSS } \\
\text { total }\end{array}$ & $\triangle \mathrm{BMI}$ \\
\hline IL-1RA T0 & $0.12(0.519)$ & $0.04(0.812)$ & $0.10(0.572)$ & $0.10(0.575)$ & $0.17(0.365)$ \\
\hline$\Delta \mathrm{IL}-1 \mathrm{RA}$ & $0.22(0.227)$ & $0.15(0.410)$ & $0.29(0.110)$ & $0.25(0.164)$ & $-0.07(0.711)$ \\
\hline IL-10 T0 & $0.07(0.711)$ & $0.11(0.558)$ & $0.04(0.807)$ & $0.04(0.821)$ & $-0.06(0.756)$ \\
\hline$\Delta \mathrm{IL}-10$ & $0.30(0.089)$ & $0.41(0.018)$ & $0.37(0.038)$ & $0.45(0.009)$ & $-0.26(0.142)$ \\
\hline
\end{tabular}

\subsection{Antipsychotic treatment effects}

We also carried out multiplex immunoassay analysis of serum from 32 patients in cohort 3 after 6 weeks of treatment with atypical antipsychotics. The treatment resulted in significant decreases in PANSS positive, negative and general scores and an average increase in BMI (Table 2). The immunoassay profiling analysis showed that IL-1RA and IL-10, which were both increased in the first onset patients, were now decreased in at least two of the antipsychotic treatment groups (Table 3). Both molecules showed significant decrease following treatment with risperidone and olanzapine (Fig. 2). Furthermore, Spearman correlation testing showed that the changes in IL-10 levels were significantly correlated with symptom improvement ( $\triangle$ PANSS) for negative, general and total scores (Table 4). Neither IL-1RA nor IL-10 showed a correlation with BMI which increased moderately (24.0 to 24.7) after the 6 week treatment period.

\section{Discussion}

This is the first meta-analysis of cytokine changes in first-onset drugnaïve schizophrenia patients compared to well-matched healthy controls across multiple clinical cohorts. All participants underwent extensive clinical assessment, and the samples were processed according to strict standard operating procedures. To achieve maximum coherence, sera from different cohorts were analysed with a robust HumanMAP immunoassay platform in a Clinical Laboratory Improvement Amendments (CLIA)-certified laboratory at Myriad-RBM Inc. (Austin, Texas). This showed that IL-1RA, IL-10 and IL-15 levels were consistently increased in first onset patients compared to controls throughout the cohorts. Furthermore, we demonstrated that the levels of IL-1RA and IL-10 were decreased after 6 weeks treatment of 32 patients with atypical antipsychotics and the change in IL-10 levels was correlated with symptom improvement. The strength of the present study was the high number of antipsychotic-naïve patients $(\mathrm{n}=180)$ and controls $(\mathrm{n}=$ 350 ) that were matched for potential confounding factors such as age, gender, BMI and smoking, and the use of a standardised assay platform.

A major consideration of this study was the heterogeneity of reported serum cytokine changes in schizophrenia. In line with this, we found that even after excluding subjects with co-morbidities and matching for potential confounding factors, cytokine variation was still apparent across the cohorts. Therefore, this variation may be dependent on other factors which have not been considered in our and other studies. In a meta-analysis carried out by Miller et al., increased levels of the pro-inflammatory cytokines IL-12, TNF- $\alpha$ and IFN- $\gamma$ were found in antipsychotic-naïve first-episode patients (Miller et al., 2011), although we found no changes in the same molecules. However, these analytes had high percentages of missing values in our study (17\% to $45 \%$ ) which could have biased our effect size estimates. Another possible explanation for this discrepancy might be the inclusion of data from nonstandardised assays or the potential presence of confounding factors in meta-analysis described above. Based on our secondary analyses, it is unlikely that the differences were caused by smoking status, cannabis use or BMI. However, other factors, such as differences in the levels of physical exercise, socioeconomic status, psychosocial stress, race, or treatment regimes in different countries, have not been controlled for in the current investigation or virtually all previous studies.

The cytokines IL-1RA and IL-10 have anti-inflammatory functions, whereas IL-15 is categorised as pro-inflammatory cytokines. Therefore the finding that both sets of molecules were increased in first onset schizophrenia patients suggests a combination of increases in pro- and anti-inflammatory pathways. This contrasts with some studies which have identified mainly pro-inflammatory changes in first onset schizophrenia patients (Miller et al., 2011), although it is consistent with others which have shown mixed responses as we have found here (Maes et al., 2002; Kunz et al., 2011; Schwarz et al., 2012).

Although we selected first-episode antipsychotic-naïve patients for this study, it still remains to be determined whether the altered cytokine levels are a cause or consequence of the disease process. Interestingly, a polymorphism in the IL-10 gene (IL10) promoter region that leads to higher production of IL-10 as well as polymorphisms in the IL-1RA gene (IL1RN) has been associated with genetic susceptibility to schizophrenia (Bocchio et al., 2002; Zanardini et al., 2003; Kim et al., 2004). These genetic studies suggest that IL-10 and IL-1RA may have a causal role in schizophrenia pathogenesis. Moreover, it is now widely accepted that peripheral immune alterations can modulate brain function. For example, peripheral infections, inflammatory responses, or injection with pro-inflammatory cytokines such as IFN- $\alpha$ can lead to altered brain and behavioural responses (Dantzer, 2004). Furthermore, animal studies have shown that peripheral injection with specific cytokines can lead to either neuroprotection or neurotoxicity, depending on the class of molecule administered (Barkhudaryan and Dunn, 1999). One study suggested that peripheral IL-15 may induce depression-like behaviour and others reported an increase of IL-15 in schizophrenia (Domenici et al., 2010; Wu et al., 2011).

The finding that IL-1RA and IL-10 levels were decreased after treatment with atypical antipsychotics suggests that these molecules might be involved in the therapeutic response to antipsychotic treatment. Indeed, reduction in IL-10 was significantly correlated with symptom improvement. As these molecules are anti-inflammatory, a reduction could signify that antipsychotics promote certain inflammatory responses. This is consistent with the findings that side-effects by atypical antipsychotics are associated with increased inflammatory markers (Dieset et al., 2012; Na et al., 2012). It has previously been shown that antipsychotics can directly modulate response of immune cells such as macrophages and microglia (Kato et al., 2011; Chen et al., 2013). Moreover, different classes of neurotransmitter receptors are expressed by immune cells and the appropriate neurotransmitters can alter cytokine responses of these cells (Idova et al., 2012; Lee, 2013). However, more complex mechanisms may be involved in the observed cytokine responses, such as the potential effect of decreased psychological stress on serum cytokine levels after antipsychotic treatment (Calcagni and Elenkov, 2006).

One limitation of the current study was the small number of cytokines investigated. This can lead to a potential bias. This procedure 
was based on the commercial availability of a multiplexed immunoassay platform and did not specifically target all key regulators of immune- and inflammation related pathways. Future studies should investigate a broader range of molecules and include those from other molecular classes such as growth factors or hormones. Another potential limitation comes from the fact that samples were not necessarily collected from participants under fasting conditions. This could be important as previous studies have shown that cytokine levels can fluctuate according to dietary intake (Blok et al., 1996). Further clinical and pre-clinical studies are required to unravel the role of cytokine alterations in schizophrenia and find strategies for better treatment approaches. Indeed, the first trials investigating therapies for schizophrenia targeting the immune system have shown promising results (Sommer et al., 2011). Evaluation of the cytokine alterations before and during treatment in these trials may help to target the relevant patient population by stratification based on these signatures, predict treatment responses to current medications and identify potential novel immunomodulatory approaches for adjunctive treatments with traditional antipsychotics.

\section{Role of funding source}

The funding agencies had no role in designing the study, the data collection, the data analysis and the preparation of the manuscript.

\section{Contributors}

LdW, ES, RK and SB designed the study. LdW and JT managed the literature searches. JT and ES performed the statistical analyses. LdW and JT wrote the first draft of the manuscript. All authors contributed to and approved the final manuscript.

\section{Conflict of interest}

JT is a consultant for Psynova Neurotech Ltd and ES, PCG, HR and SB are consultants for Myriad-RBM, although this does not interfere with policies of the journal regarding sharing of data or materials.

\section{Acknowledgements}

This study was supported by the Virgo Consortium, funded by the Dutch government project number FES0908; by The Netherlands Genomics Initiative (NGI) project number 050-060-452; by the Stanley Medical Research Institute (SMRI); by the European Union FP7 SchizDX research programme (grant reference 223427) and by the Dutch Fund for Economic Structure Reinforcement, the NeuroBasic PharmaPhenomics project (no. 0908). JT is supported by the Dutch Fund for Economic Structure Reinforcement, the NeuroBasic PharmaPhenomics project (no. 0908).

\section{References}

Barkhudaryan, N., Dunn, A.J., 1999. Molecular mechanisms of actions of interleukin-6 on the brain, with special reference to serotonin and the hypothalamo-pituitaryadrenocortical axis. Neurochem. Res. 24, 1169-1180.

Blok, W.L., Katan, M.B., van der Meer, J.W., 1996. Modulation of inflammation and cytokine production by dietary (n-3) fatty acids. J. Nutr. 126, 1515-1533.

Bocchio, C.L., Boin, F., Zanardini, R., Popoli, M., Michelato, A., Bignotti, S., Tura, G.B., Gennarelli, M., 2002. Association between promoter polymorphic haplotypes of interleukin-10 gene and schizophrenia. Biol. Psychiatry 51, 480-484.

Bossuyt, P.M., Reitsma, J.B., 2003. The STARD initiative. Lancet 361, 71.

Calcagni, E., Elenkov, I., 2006. Stress system activity, innate and T helper cytokines, and susceptibility to immune-related diseases. Ann. N. Y. Acad. Sci. 1069, 62-76.

Chan, M.K., Guest, P.C., Levin, Y., Umrania, Y., Schwarz, E., Bahn, S., Rahmoune, H., 2011 Converging evidence of blood-based biomarkers for schizophrenia: an update. Int. Rev. Neurobiol. 101, 95-144.

Chen, M.L., Wu, S., Tsai, T.C., Wang, L.K., Tsai, F.M., 2013. Regulation of macrophage immune responses by antipsychotic drugs. Immunopharmacol. Immunotoxicol. 35, 573-580.

Cliff, N., 1993. Dominance statistics: ordinal analyses to answer ordinal questions. Psychol. Bull. 114, 494-509.

Dalman, C., Allebeck, P., Gunnell, D., Harrison, G., Kristensson, K., Lewis, G., Lofving, S., Rasmussen, F., Wicks, S., Karlsson, H., 2008. Infections in the CNS during childhood and the risk of subsequent psychotic illness: a cohort study of more than one million Swedish subjects. Am. J. Psychiatry 165, 59-65.

Dantzer, R., 2004. Cytokine-induced sickness behaviour: a neuroimmune response to activation of innate immunity. Eur. J. Pharmacol. 500, 399-411.

Davies, G., Welham, J., Chant, D., Torrey, E.F., McGrath, J., 2003. A systematic review and meta-analysis of Northern Hemisphere season of birth studies in schizophrenia. Schizophr. Bull. 29, 587-593.

Dieset, I., Hope, S., Ueland, T., Bjella, T., Agartz, I., Melle, I., Aukrust, P., Rossberg, J.I., Andreassen, O.A., 2012. Cardiovascular risk factors during second generation antipsychotic treatment are associated with increased C-reactive protein. Schizophr. Res. 140, 169-174.

Domenici, E., Wille, D.R., Tozzi, F., Prokopenko, I., Miller, S., McKeown, A., Brittain, C., Rujescu, D., Giegling, I., Turck, C.W., Holsboer, F., Bullmore, E.T., Middleton, L., Merlo-Pich, E., Alexander, R.C., Muglia, P., 2010. Plasma protein biomarkers for depression and schizophrenia by multi analyte profiling of case-control collections. PLoS One 5, e9166.

Doorduin, J., de Vries, E.F., Willemsen, A.T., de Groot, J.C., Dierckx, R.A., Klein, H.C., 2009 Neuroinflammation in schizophrenia-related psychosis: a PET study. J. Nucl. Med. 50, 1801-1807.

Drexhage, R.C., Knijff, E.M., Padmos, R.C., Heul-Nieuwenhuijzen, L., Beumer, W., Versnel, M.A., Drexhage, H.A., 2010. The mononuclear phagocyte system and its cytokine inflammatory networks in schizophrenia and bipolar disorder. Expert. Rev. Neurother. $10,59-76$.

Drexhage, R.C., Hoogenboezem, T.A., Cohen, D., Versnel, M.A., Nolen, W.A., van Beveren, N.J., Drexhage, H.A., 2011a. An activated set point of T-cell and monocyte inflammatory networks in recent-onset schizophrenia patients involves both pro- and antiinflammatory forces. Int. J. Neuropsychopharmacol. 14, 746-755.

Drexhage, R.C., Weigelt, K., van Beveren, N.J., Cohen, D., Versnel, M.A., Nolen, W.A. Drexhage, H.A., 2011b. Immune and neuroimmune alterations in mood disorders and schizophrenia. Int. Rev. Neurobiol. 101, 169-201.

Eaton, W.W., Byrne, M., Ewald, H., Mors, O., Chen, C.Y., Agerbo, E., Mortensen, P.B., 2006 Association of schizophrenia and autoimmune diseases: linkage of Danish national registers. Am. J. Psychiatry 163, 521-528.

Efron, B., 1987. Better bootstrap confidence intervals. J. Am. Stat. Assoc. 82, 171-185.

Idova, G.V., Alperina, E.L., Cheido, M.A., 2012. Contribution of brain dopamine, serotonin and opioid receptors in the mechanisms of neuroimmunomodulation: evidence from pharmacological analysis. Int. Immunopharmacol. 12, 618-625.

Kato, T.A., Monji, A., Mizoguchi, Y., Hashioka, S., Horikawa, H., Seki, Y., Kasai, M., Utsumi, H., Kanba, S., 2011. Anti-inflammatory properties of antipsychotics via microglia modulations: are antipsychotics a 'fire extinguisher' in the brain of schizophrenia? Mini Rev. Med. Chem. 11, 565-574.

Kay, S.R., Fiszbein, A., Opler, L.A., 1987. The positive and negative syndrome scale (PANSS) for schizophrenia. Schizophr. Bull. 13, 261-276.

Kim, S.J., Lee, H.J., Koo, H.G., Kim, J.W., Song, J.Y., Kim, M.K., Shin, D.H., Jin, S.Y., Hong, M.S. Park, H.J., Yoon, S.H., Park, H.K., Chung, J.H., 2004. Impact of IL-1 receptor antagonist gene polymorphism on schizophrenia and bipolar disorder. Psychiatr. Genet. 14, 165-167.

Kromrey, J.D., Hogarty, K.Y., Ferron, J.M., 2005. Robustness in meta-analysis: an empirical comparison of point and interval estimates of standardized mean differences and cliff's delta. Proceedings of the American Statistical Association Joint Statistical Meetings.

Kunz, M. Cereser, K.M. Goi, P.D., Fries, G.R. Teixeira, A.L, Fernandes, B.S., Belmonte-deAbreu, P.S., Kauer-Sant'Anna, M., Kapczinski, F., Gama, C.S., 2011. Serum levels of IL-6, IL-10 and TNF-alpha in patients with bipolar disorder and schizophrenia: differences in pro- and anti-inflammatory balance. Rev. Bras. Psiquiatr. 33, 268-274.

Lee, M., 2013. Neurotransmitters and microglial-mediated neuroinflammation. Curr Protein Pept. Sci. 14, 21-32.

Maes, M., Bocchio, C.L., Bignotti, S., Battisa Tura, G.J., Pioli, R., Boin, F., Kenis, G., Bosmans, E., de Jongh, R., Altamura, C.A., 2002. Increased serum interleukin-8 and interleukin10 in schizophrenic patients resistant to treatment with neuroleptics and the stimulatory effects of clozapine on serum leukemia inhibitory factor receptor. Schizophr. Res. 54, 281-291.

Maino, K., Gruber, R., Riedel, M., Seitz, N., Schwarz, M., Muller, N., 2007. T- and Blymphocytes in patients with schizophrenia in acute psychotic episode and the course of the treatment. Psychiatry Res. 152, 173-180.

Miller, B.J., Buckley, P., Seabolt, W., Mellor, A., Kirkpatrick, B., 2011. Meta-analysis of cytokine alterations in schizophrenia: clinical status and antipsychotic effects. Biol. Psychiatry 70, 663-671.

Muller, N., Schwarz, M.J., 2010. Immune system and schizophrenia. Curr. Immunol. Rev. 6, 213-220.

Na, K.S., Kim, W.H., Jung, H.Y., Ryu, S.G., Min, K.J., Park, K.C., Kim, Y.S., Yoon, J.S., Ahn, Y.M., Kim, C.E., 2012. Relationship between inflammation and metabolic syndrome following treatment with paliperidone for schizophrenia. Prog. Neuropsychopharmacol. Biol. Psychiatry 39, 295-300.

O'Connor, M.F., Bower, J.E., Cho, H.J., Creswell, J.D., Dimitrov, S., Hamby, M.E., Hoyt, M.A. Martin, J.L., Robles, T.F., Sloan, E.K., Thomas, K.S., Irwin, M.R., 2009. To assess, to control, to exclude: effects of biobehavioral factors on circulating inflammatory markers. Brain Behav. Immun. 23, 887-897.

Ottervald, J., Franzen, B., Nilsson, K., Andersson, L.I., Khademi, M., Eriksson, B., Kjellstrom, S., Marko-Varga, G., Vegvari, A., Harris, R.A., Laurell, T., Miliotis, T., Matusevicius, D. Salter, H., Ferm, M., Olsson, T., 2010. Multiple sclerosis: identification and clinical evaluation of novel CSF biomarkers. J. Proteomics 73, 1117-1132.

Park, H.S., Park, J.Y., Yu, R., 2005. Relationship of obesity and visceral adiposity with serum concentrations of CRP, TNF-alpha and IL-6. Diabetes Res. Clin. Pract. 69, 29-35.

Pedersen, M.S., Benros, M.E., Agerbo, E., Borglum, A.D., Mortensen, P.B., 2012. Schizophrenia in patients with atopic disorders with particular emphasis on asthma: a Danish population-based study. Schizophr. Res. 138, 58-62.

Potvin, S., Stip, E., Sepehry, A.A., Gendron, A., Bah, R., Kouassi, E., 2008. Inflammatory cytokine alterations in schizophrenia: a systematic quantitative review. Biol. Psychiatry 63, 801-808.

Schwarz, E., Izmailov, R., Spain, M., Barnes, A., Mapes, J.P., Guest, P.C., Rahmoune, H., Pietsch, S., Leweke, F.M., Rothermundt, M., Steiner, J., Koethe, D., Kranaster, L., Ohrmann, P., Suslow, T., Levin, Y., Bogerts, B., van Beveren, N.J., McAllister, G., Weber, N., Niebuhr D., Cowan, D., Yolken, R.H., Bahn, S., 2010. Validation of a blood-based laboratory tes to aid in the confirmation of a diagnosis of schizophrenia. Biomark. Insights 5, 39-47. 
Schwarz, E., Guest, P.C., Rahmoune, H., Harris, L.W., Wang, L., Leweke, F.M., Rothermundt, M., Bogerts, B., Koethe, D., Kranaster, L., Ohrmann, P., Suslow, T., McAllister, G., Spain, M., Barnes, A., van Beveren, N.J., Baron-Cohen, S., Steiner, J., Torrey, F.E., Yolken, R.H., Bahn, S., 2012. Identification of a biological signature for schizophrenia in serum. Mol. Psychiatry 17, 494-502.

Sommer, I.E., de Witte, L., Begemann, M., Kahn, R.S., 2011. Nonsteroidal antiinflammatory drugs in schizophrenia: ready for practice or a good start? a metaanalysis. J. Clin. Psychiatry 73, 414-419.

Stefansson, H., Ophoff, R.A., Steinberg, S., Andreassen, O.A., Cichon, S., Rujescu, D., Werge T., Pietilainen, O.P., Mors, O., Mortensen, P.B., Sigurdsson, E., Gustafsson, O., Nyegaard, M., Tuulio-Henriksson, A., Ingason, A., Hansen, T., Suvisaari, J., Lonnqvist, J., Paunio, T. Borglum, A.D., Hartmann, A., Fink-Jensen, A., Nordentoft, M., Hougaard, D., NorgaardPedersen, B., Bottcher, Y., Olesen, J., Breuer, R., Moller, H.J., Giegling, I., Rasmussen, H.B., Timm, S., Mattheisen, M., Bitter, I., Rethelyi, J.M., Magnusdottir, B.B., Sigmundsson, T., Olason, P., Masson, G., Gulcher, J.R., Haraldsson, M., Fossdal, R., Thorgeirsson, T.E., Thorsteinsdottir, U., Ruggeri, M., Tosato, S., Franke, B., Strengman, E., Kiemeney, L.A., Melle, I., Djurovic, S., Abramova, L., Kaleda, V., Sanjuan, J., de Frutos, R., Bramon, E., Vassos, E., Fraser, G., Ettinger, U., Picchioni, M., Walker, N., Toulopoulou, T., Need, A.C., Ge, D., Yoon, J.L., Shianna, K.V., Freimer, N.B., Cantor, R.M., Murray, R., Kong, A., Golimbet, V., Carracedo, A., Arango, C., Costas, J., Jonsson, E.G., Terenius, L., Agartz, I., Petursson, H., Nothen, M.M., Rietschel, M., Matthews,
P.M., Muglia, P., Peltonen, L., St. Clair, D., Goldstein, D.B., Stefansson, K., Collier, D.A., 2009. Common variants conferring risk of schizophrenia. Nature 460, 744-747.

van Berckel, B.N., Bossong, M.G., Boellaard, R., Kloet, R., Schuitemaker, A., Caspers, E., Luurtsema, G., Windhorst, A.D., Cahn, W., Lammertsma, A.A., Kahn, R.S., 2008. Microglia activation in recent-onset schizophrenia: a quantitative (R)-[11C]PK11195 positron emission tomography study. Biol. Psychiatry 64, 820-822.

Wagner, C., Visvanathan, S., Braun, J., van der Heijde, D., Deodhar, A., Hsu, B., Mack, M., Elashoff, M. Inman, R.D., 2012. Serum markers associated with clinical improvement in patients with ankylosing spondylitis treated with golimumab. Ann. Rheum. Dis. 71, 674-680.

Wu, X., Hsuchou, H., Kastin, A.J., He, Y., Khan, R.S., Stone, K.P., Cash, M.S., Pan, W., 2011. Interleukin-15 affects serotonin system and exerts antidepressive effects through IL15Ralpha receptor. Psychoneuroendocrinology 36, 266-278.

Zanardini, R., Bocchio-Chiavetto, L., Scassellati, C., Bonvicini, C., Tura, G.B., Rossi, G., Perez, J., Gennarelli, M., 2003. Association between IL-1beta -511C/T and IL-1RA (86 bp)n repeats polymorphisms and schizophrenia. J. Psychiatr. Res. 37, 457-462.

Zhang, X.Y., Cao, L.Y., Song, C., Wu, G.Y., Chen, d.C., Qi, L.Y., Wang, F., Xiu, M.H., Chen, S., Zhang, Y., Lu, L., Kosten, T.A., Kosten, T.R., 2008. Lower serum cytokine levels in smokers than nonsmokers with chronic schizophrenia on long-term treatment with antipsychotics. Psychopharmacology (Berl) 201, 383-389. 